ACCEPTED VERSION - SUBJECT TO PROOFS

Forthcoming in Sociology - Special issue on Sociologies of Everyday Life

Sociology 1-16 (C) The Author(s) 2015 DOI: 10.1177/0038038515577910 soc.sagepub.com

\title{
Object Relations in Accounts of Everyday Life
}

\author{
Jenny Rinkinen \\ Aalto University School of Business, Finland \\ Mikko Jalas \\ Aalto University School of Arts, Design and Architecture, Finland \\ Elizabeth Shove \\ Lancaster University, UK
}

\begin{abstract}
Theories of social practice routinely acknowledge the significance of the material world, arguing that objects have a constitutive role in shaping and reproducing the practices of which daily life is made. Objects are also important for those who approach 'everyday life' as an ontology, a tradition in which scholarly interest in the material reaches beyond the somewhat pragmatic concerns of practice theory. In this paper we identify traces of both schools of thought in the ways in which people describe their immediate material environments. By drawing on an archive of diary material, we illustrate multi-faceted object relations with reference to the example of keeping warm. We conclude that in keeping warm, diarists weave together encounters, tactics and judgements, encountering objects in ways that extend beyond the 'mere' enactment of social practice. In analysing these encounters we explore ways of conceptualising the object-world that are especially relevant for studies of everyday life.
\end{abstract}

\section{Keywords}

diary archives, materiality, object relations, social practice 


\section{Introduction}

Understanding how things, day-to-day practices and practitioners are mutually coaligned is a core concern for sociologists of everyday life. Theories of social practice have recently entered this field, bringing with them a new emphasis on the constitutive role of objects. Following actor network theory (Latour, 1992), materials and social arrangements are frequently analysed together on the grounds that both are implicated in the emergence, the enactment and the reproduction of everyday life (Shove et al., 2012).

In contrast to those who study the culturally and symbolically significant surfaces of objects, practice theorists contend that the social significance of material objects lies in the ways in which they are 'handled' (Reckwitz, 2002a: 210; Reckwitz, 2002b) in how they are mobilised in practice and how they combine in practice-arrangement nexuses (Schatzki, 2010). Ingold $(2008,2012)$ takes these ideas a step further, suggesting that analyses of material culture should focus less on the 'objectness' of things and more on the material flows and formative processes through which they come into being. This writing focuses on things in use, recognising that usefulness is always in flux, that it depends on how objects relate to each other, and how they are integrated into one or more practices. In keeping with these ideas, Warde's proposition that consumption happens not for its own sake but as part of one or another social practice establishes the ontologi- cal standing of goods as elements of practice (Warde, 2005). More detailed work high- lights specific forms of object-engagement such as maintenance (Gregson et al., 2009) or construction (Watson and Shove, 2008). Relations between objects have also been considered, as in Hand and Shove's (2007) analysis of the freezer as an orchestrating node around which multiple aspects of consumption and provision converge. In combination, studies like these generate convincing and compelling accounts of the dynamic relation between practices and materiality but in concentrating on aspects of function and flow they tend to overlook the many other parts things play in daily life.

As Schatzki notes, the ways in which people discuss and act towards objects are not exhausted by questions of use: 'People also observe objects, examine them, measure them, admire them, draw them, and talk about them in numerous ways that do not pertain to use' (1996: 114). These modes of engagement are not somehow apart from the conduct of practice, nor are they 'purely' symbolic. This has been acknowledged in sociological inquiries. For example, Durkheim (1915) notes that sacred objects have a special role in religious rituals; Goffman (1967) and later Collins (2004) recognise the social significance of objects in more mundane forms of human interaction; and in the field of consumption, writers like Douglas and Isherwood (1980) and Belk (1988) analyse the fluid status of objects as they are produced, consumed, exchanged, appreciated and categorised in aesthetic, emotional and economic terms (see also Becker, 1974, 1980). Yet, to date, and with a few exceptions (e.g. Appadurai, 1988; Engeström and Blackler, 2005), there has been relatively little discussion of how these multiple object relations are reproduced in everyday practice.

One method of catching sight of the complexity of object relations is to review ordi- nary people's accounts of an ordinary day. In this paper we examine co-existing forms of practice-object relations with the help of a body of solicited diary data created through 
two successive calls in which volunteers were invited to document an ordinary day. This diary-keeping exercise was organised by the Finnish Literature Society and took place in 1999 and again in 2009. In working with the resulting archive of diary entries we look for theoretical insight - and not 'just' documentary evidence - regarding relations between things, practices and the constitution of everyday life. In other words, our method is to treat the diarists as 'everyday theorists' and to tap into narratives that reveal complex and yet distinctive methods of conceptualising the parts things play in the reproduction, the experience and the reporting of the everyday.

In brief, our ambition is to review empirical accounts of everyday life to see how object relations are represented. We limit our analysis to descriptions of keeping warm on a cold day. Within the diary data, the sayings and doings that relate to staying warm stand out as a broad category not only of practical activity but also of feeling, tradition and evaluation. Other topics might have worked as well: we do not claim that the prac- tices of staying warm are in some way unique, nor do we suggest that this case gives us access to all possible forms of object relations. Rather, we use this theme as a focal point for an exercise in discerning the multiple, dynamic and co-existing roles of things within and beyond matters of practicality and use (Ingold, 2012).

In working with the Finnish diary data, and in harking back to the French tradition of everyday life studies, we hope to enrich social theories of practice and contribute to an understanding of object relations within the sociology of everyday life. In detail, the paper is organised as follows: we begin by discussing the use of diaries and their relevance within theoretical traditions that treat the everyday as a particular ontological category. We then say more about the texts to which we refer, the modes of material engagement they represent, and the insights that can be drawn from these lay accounts of object relations. We conclude by reflecting on the wider implications of our analysis.

\section{Using Diaries as a Method of Conceptualising and Representing Everyday Life}

Scholarly practices frequently imply and just as frequently reproduce a division between elite intellectuals on the one hand and lay people, who are the objects of study, on the other. Although this tendency has been noted and deliberately resisted, for instance by Garfinkel (1996), academic researchers claim to have a privileged view of social processes and of social order. The tradition of everyday life studies challenges this paradigm. It does so in that scholars operating within this field aim to provide methods and conceptual frameworks that are capable of accounting for the everyday world as that is seen, understood and enacted by lay people. This is not an easy task. Indeed, some argue that established research methods are always lagging behind and always too selective to grasp more than a fraction of the richness, the complexity and the fleeting character of the everyday (Highmore, 2002; Sheringham, 2006).

Whilst the immediacy of daily life might elude researchers in pursuit of stable, rationalist accounts, it is not necessarily immune to all forms of representation. Put bluntly, methods of registering the everyday depend on recognising and not resisting these necessarily provisional features (Pink, 2012). As Highmore (2002: 171) explains: 'the singular- 
ity, the here-and-now-ness of everyday life requires invention in a variety of ways [...] for making the everyday vivid, of rescuing it from an undifferentiating scrutiny'. For this, De Certeau (1984) suggests a range of techniques: foregrounding and revealing the absence and occultation of the everyday; recovering textual remains; and recording detail. Diaries constitute one such method (Lefebvre, 1947), and have been widely used in this role (Crang, 2005; Sheringham, 2006). Similar to lay utterances, patchy, sporadic diary entries represent theorising that has its starting point in first-hand experience of the everyday.

Diaries, along with other literary genres, are potentially capable of bringing small details to life (De Certeau, 1984; Highmore, 2001), uncovering the self-evident and revealing repetition and sameness (Lejeune, 2009). While diaries have been used to cap- ture the mundane, the taken for granted and the recurrent qualities of day-to-day life, they have not, as far as we know, been used as a resource with which to problematise or reveal the role of things. Before embarking on such an exercise we briefly review the problems and benefits of working with diary data in this way.

\section{Using Diaries in Research}

Diaries take many forms, ranging from unstructured personal accounts to more organised texts produced in response to specific 'directives'. In addition, there are established research traditions in which people are invited to keep diaries of travel, of weather or of health, and in which the resulting data are aggregated and analysed for different purposes (Alaszewski, 2006). Diaries also feature in studies of human geography (Meth, 2003; Morrison, 2012), and in feminist research - a field in which there has been further discussion of diaries as tools of self-reflection and empowerment (Jokinen, 2004; Stanley, 1995).

In these, as in other settings, diary writing is governed by a range of conventions, one of which is the regularity of observations. This stems from the ambition of detecting and recording longitudinal changes; for example, in one's health or in the environment (Oliver, 1958). Although we work with one-day diaries, many entries are informed by this tradition. A second generic feature of diary keeping is its privacy. Diary writing provides opportunities for personal reflection and development and for expressing thoughts which are not for sharing, at least not immediately. Insofar as the diarist is personally inscribed in the diary, rules of self-presentation affect the text, and probably do so whether there is an intention to publish or not. A third tendency - which is for diaries to foreground the materially and emotionally proximal (Lejeune, 2009) - underpins their emphasis on the familiar, the habitual and the intimate (Highmore, 2001: 15). Finally, diaries often follow the same narrative structure, typically starting in the morning, sometimes outlining plans for the day, then coming to a close with the evening and with thoughts that drift on to other topics or to far-off places.

It would be misleading to say that diaries provide authentic access to real life or that they are free from systems and structures of representation (Latham, 2003). The details that diarists provide are often inconsistent, patchy, partial and fragmented. This is not surprising; after all, their lay authors are not bound by scientific conventions, nor are they (usually) under any obligation to make reliable observations. In addition, and since 
diaries are necessarily singular accounts rooted in the conditions of their production, much is lost when they are read and interpreted out of context (Meth, 2003).

When viewed from the perspective of the French tradition of everyday life studies, these are not necessarily negative features. Instead, the fact that diaries are frequently ambivalent or that they represent events and moments in terms which fall outside dominant discourses and rationalities is something to be valued. In these respects, diaries are especially useful in revealing experiences that are always emerging and always uncertain (Sheringham, 2006). In addition, and again following De Certeau (1984), various commentators argue that the purpose of enquiring into the realm of the everyday is not to preserve it, but rather to (re)invent it: diary writing is thus seen as a generative and productive endeavour in its own right.

Having commented on the qualities of diary material in general terms, we now introduce the documents on which this paper is based. We make use of an archive of one-day diaries written by ordinary Finns in response to a call from the Finnish Literature Society to document a single day, 2 February: first in 1999, and again in 2009. Unlike the UK Mass-Observation directives, both calls were very open: participants were simply invited to write about the 'Ordinary day of the Finn'. There were no further guidelines about what to describe or to whom the writing should be addressed. The diaries submit- ted in response exemplify all the conventions outlined above: personal reflections and accounts of special projects exist alongside detailed reports of the weather, of natural phenomena, of the respondents' immediate surroundings and of social issues.

We approached this data set by reading a selection of entries. Our first selection of approximately 8000 diary pages was guided by an interest in descriptions that were in some way related to the ambiguous notion of energy. This led us to collect extracts and vignettes relating to a variety of activities including heating, showering, cooking and climate-related observations (see Jalas and Rinkinen, 2013). To be more precise, we read 7300 diary pages from the 1999 material, and wrote down 391 vignettes. From the 2009 material we read 1000 pages, and wrote down 160 vignettes. The quantitative imbalance between the two years reflects the smaller size of the 2009 data set $(11,503$ compared with 23,500 entries), reflecting the fact that this second round was not as widely publicised. There were also differences in how diary entries were indexed, meaning that the 1999 call was easier to work with. For purposes of the present discussion, these features are not significant in that we do not compare the two years. We treat the diarists anonymously and refer to the extracts with numbers: the numbering of the diaries in 1999 is made by the archive, the numbering of the extracts from 2009 is based on our own records. The preliminary exercise of identifying and recording energy-related vignettes was followed by a further round of selection and reading in which we concentrated on entries that dealt with the practices of heating the home (approximately 150 vignettes). This second step highlighted the significance of materials and of object relations, which is the topic to which we now turn. 


\section{Materiality and Temporality in the Diary Archive}

In discussing diary entries, we distinguish between three co-existing modes of material engagement. Before introducing these modes we begin with two general observations. First, although the diarists write in very different ways, the diary format clearly structures the manner in which materials and object relations are represented. Diarists tend to foreground the micro-situatedness of the everyday. In so doing, many write pragmatically, recounting the events of the day by explaining what happened when and how. At the same time, the diary genre provides license for more reflective narratives, and for commenting on those same events in depth and in a more intimate manner. Texts often switch between matter of fact reporting and thoughtful commentary.

Second, diarists hold different temporalities of material engagement in tension. The sameness of everyday life and its rhythmic quality underpins an anticipation and appreciation of the known and the familiar. Although continuity is presumed, descriptions of the day are typically fragmented: episodes are presented with little reference either to spatial context or to factual temporal sequence. In general, diarists do not provide elaborate causal narratives, nor do they stray far beyond the immediacy of the moment. Things simply exist - and are simply engaged within the responsive, instantaneous 'time' of the everyday (Highmore, 2002). And yet it is evident that responses, or in De Certeau's terms, tactics of coping are established over time, and, as such, call for a temporally extended, somewhat historical analysis (De Certeau, 1984). In selecting events, observations and ideas that are worth reporting, diarists are actively engaged in positioning practices and their elements in some temporal and spatial frame. In addition, diarists are, of necessity, involved in sharing knowledge, experience and evaluations with some future reader (Lejeune, 2009). In these various ways, and almost despite itself, the diary format situates the events of the 'day' within a longer time frame.

These generic features co-exist alongside three distinctive modes of representing the object-world. Our reading of diary entries on the topic of heating and keeping warm led us to identify descriptions in which diarists (1) encounter the object-world, (2) act in a materially constituted world (carrying out practices) and (3) evaluate the object-world. All three modes are widespread, they are not unique to one diarist or another, and they often co-exist within diary entries - and even within the same vignette. In what follows we use selected excerpts to illustrate these modes and to suggest that each represents a temporally distinct way of relating to objects.

\section{Encountering the Object-World: The Weather, the Heating System, the Firewood}

It is almost midnight. The wind howls in the corners and in the ventilation pipes ever more loudly. The snow blowing over the roof has piled on the windowsill up to half-curtains. It is wonderful to think of sneaking underneath the blanket. Inside the heat of the oven is level. (SKS KRA, 1999: 42463)

Descriptive texts like this revolve around the perception, recognition and naming of entities. Diarists operating in this genre list the people, places and things that form and 
fill their day. Some of these accounts resemble Charles Perec's extreme attempts to capture the everyday through the repeated cataloguing of objects in urban spaces (Sheringham, 2006). More commonly, such texts consist of seemingly neutral inventories of what the author sees in situ, and in the moment. There is no reference to memory, no attempt at narrative integration, and no ambition to do more than record what is 'there' (Crang, 2005). And yet these descriptions are unavoidably analytical: each item mentioned is an item that for one reason or another counts as something that is worth a mention. This significance often relates to some causal or diagnostic connection. In other words, items are referred to because they are thought to be relevant in identify- ing and perhaps explaining other phenomena.

As in the excerpt above, and also in general, emotional or sensual thought figures as a particular form of self-observing, as when people comment on their preferences or simply state that they like some things. In accounts of this nature there is an element of distancing from the practicalities and problems of everyday life, a feature which highlights the point that this mode of material engagement is simply not action oriented.

As well as describing the material world, documentary accounts sometimes refer to the author as an element in the scene that is represented. This does not necessarily mean that humans are granted any special agency or purpose in what remain characteristically blank forms of reportage. In the next extract, the diarist comments on the wear and tear on his/her body as if this was just another part of the system of heating.

After four o'clock I harden my mind. The frost has hit minus fourteen degrees, but one has to drag oneself to the wood pile. My back is not agreeing with this and the fingers get cold, but the remaining firewood is of such a size that it needs to be chopped. I manage to make half a wheelbarrow of chopped wood and get an idea to heat the sauna. (SKS KRA, 1999: 41200)

Even though authors refer to things that are merely present-at-hand, they are not entirely indifferent to the objects they describe. They can be evaluative and point to aesthetic and other virtues (and vices) but the point is that they do so without reference to particular uses, affordances or human interests.

The frost meter indicates $21.5 \mathrm{C}$. The radio confirms the degrees. I glance at the fireplace, put more wood in and enjoy the radiating heat. My eyes follow the play of the flames and I recall the many number of camp fires in the woods. FIRE is after all the best of all inventions. (SKS KRA, 1999: 42341)

In this mode of encountering the object-world, there is an ever-present, but implicit, spatial emphasis on proximate things such as the frost meter. Descriptions of this type are confined by a sort of 'activity-place space that is a matrix of places and spaces where activities are performed' (Schatzki, 2002: 43). The temporal frame is just as constricted. There is no mention of what Schatzki (2002: 45) refers to as forms of 'prefiguration' that is, of how present material arrangements make future combinations easier or harder to achieve - and no mention of history or of causation. Descriptions are characteristically matter of fact, and in the present.

It's cold inside. I place logs in the stove and a matchstick in the curly birchbark, porridge water in 
the pot, and morning coffee in the kettle. [...] The kitchen warms up, the porridge water boils. The day can begin. (SKS KRA, 2009: 96)

Being at home I usually heat with wood and the electric radiators can cool down. When the fire was going well I felt so drowsy I went to lie down on the bed. (SKS KRA, 2009: 17)

Reading a book I noticed that the living room was quite cold and I put woollen socks knitted by my daughter on top of a thinner pair. (SKS KRA, 2009: 31)

Like the flux of street-talk to which De Certeau refers (1984), this mode of writing represents a form of haphazard and random documenting. As such it is perhaps best understood not as a representation of personal mental processes but as a particularly open way of being-in-the-world, and as an essentially aesthetic form of expression. This suggests that aesthetic orderings might encompass residual bits and pieces that do not fit into more purposeful schemes and categories of practical action. Alternatively, we might conclude that this mode of encountering the object-world allows us to catch sight of material entities not as entities that act, but as the 'media in which living things are immersed, and are experienced by way of their currents, forces and pressure gradients' (Ingold, 2012).

To reiterate, in this kind of object-oriented writing, things are observed and named but descriptions of action, logical reasoning and moral judgement are only tentatively present (Thévenot, 2001).

\section{Acting in a Materially Constituted World: Coping with the Cold}

Accounts of practical, on-going and responsive problem-solving represent a second mode of material engagement. Within social theory, practices are integrative structures that delineate the means and process of doing, and that simultaneously reproduce proper and desirable ends, aims and orientations (Schatzki, 2002). Diarists' descriptions of acting in a materially constituted world reproduce this double orientation. Materials consequently figure as tools required for the enactment of specific practices, and as instruments that can be handled in variously effective ways. On both counts, material surroundings are noted and noteworthy because they are actionable.

When operating within this more pragmatic tradition, diarists write about how to do things and how to handle objects so as to meet the 'standards' of the practices in which they are engaged. Not surprisingly, economic and practical aspects come to the fore in reports in which people describe methods of keeping warm. The following excerpt exemplifies this approach.

Frost appears to be $-26 \mathrm{C}$. I point out to my man that it is wise to connect the car preheating [electric heating of the engine], because he intends to drive to the city. [...] I light up the fireplace, the wood is already in there. Dry, warm wood lights up easily. We enjoy breakfast. I go back to bed and read the newspaper. My man goes to light up the boiler of the central heating, so that the house would be warm, now that there is the small baby. I stand up to add wood to the fireplace. (SKS KRA, 1999: 41978)

In this case, there is a lot of planning and causal explanation. Heating systems are needed 
to make other things possible (getting the car started) or to make people comfortable (particularly the baby). Things are described in a synchronised, sequential manner following the series of actions in which they have a part. These deliberate actions are, in turn, organised around pre-defined goals; for example, remembering to dry sticks in the oven so that it is easier to light the fire the next day.

As described below, the outside weather, and particularly the cold air, creates specific demands, mattering for how practices are enacted, sequenced and coordinated.

In the morning the meter showed 15 degrees frost, so it was a proper day for baking and cooking. (SKS KRA, 1999: 41694)

I put the dishes into the machine, and it is full since there was already some from yesterday. I can set the machine running to get hot water to the drain. (SKS KRA, 1999: 42214)

After getting up [from a nap] I clean out the ashes from last night, get a basket full of logs from the cellar, and stack the fireplace ready for the next fire. (SKS KRA, 2009: 78)

Schatzki (2001) and Warde (2005) contend that pre-existing practices-as-entities are reproduced and transformed through repeated doings and sayings and recurrent performances. The diarists' accounts quoted here are consistent with this view, and with Bourdieu's claims that the world of practice is a world already populated by procedures to be followed and paths to be taken (Bourdieu, 1990: 53). In writing about what they do, diarists mobilise understandings of competent action within pre-existing material and social conditions. Sometimes these accounts focus on inconvenience and trouble, or on how problems have been confronted and solved, but in other cases all goes well: the pieces of the daily jigsaw slot into place. In these situations, agency, materiality and shared conventions mesh (Thévenot, 2001).

When writing in this mode, diarists write about reciprocal relations between objects and humans. Material elements call for, carry and preserve forms of practical competence. Practical competences are initially craft-based, embedded and locally reproduced but as practices (and related materials) become more widely shared, related competences stabilise, sometimes to the point that they can be defined, taught and learned regardless of the situation (Shove et al., 2012: 50). In focusing on how practices are enacted, some entries represent a form of peer-to-peer user instruction and, as such, play a role in keeping knowledge in circulation (Shove et al., 2012; Thévenot, 2001).

Practice-theoretical studies of how daily life is reproduced and enacted in an alwayschanging environment refer to dynamic processes that characterise on-going sequences and chains of action (Southerton, 2006). In writing about how they 'play the game' according to pre-existing rules, and about how they excel and 'score' in everyday life, diarists show themselves to be knowledgeable and strategic actors within the ends delineated by their habitus. In the most positive of these accounts, things are skilfully mobilised within a seamless flow of effective action, taking their place in the smooth running of everyday life. 


\section{Evaluating the Material World: How Heating Should be Done}

While some diary entries are full of confidence others are riddled with uncertainty, also reporting on strains, tensions and outright conflict about how things should be done. Tactical ways of doing and coping do not always correspond to shared understandings of how life should be lived. There are, in addition, situations in which new materials or forms of knowledge disrupt existing routines and throw established habits out of kilter (De Certeau, 1984). Moreover, every method of handling the practical details of daily life is linked, in some way, to broader conditions and consequences. These challenges underpin the third mode of material engagement evident in the diary data.

This mode is given expression when diarists justify or question particular practices and uses of objects. In this kind of writing, accounts of practice (for instance in the form of peer-to-peer talk and 'user instructions') invoke or refer to an evaluative framework. Descriptions of how to keep warm are consequently presented and situated in terms of an understanding of proper 'standards'; for example, of comfort or frugality (Thévenot, 2001).

Such engagement is not aesthetic; it is not a matter of explaining how to do things, nor is it a disinterested description of how things are. Instead, accounts are infused with normative evaluation, affirming or challenging the worth of specific practical-material arrangements or of entire ways of living. Judgements of good and bad do not relate to private matters of convenience, ease or joy but instead refer to the wider conditions and consequences of the action. In short, this mode introduces the public eye of a 'generalised other' (Thévenot, 2001).

Evaluative reflexivity implies critical distancing from one's own action: in the diary material, judgements reflect a variety of distant concerns including family traditions, the wider society or animal welfare. On the other hand, reflexivity can also prompt people to think again about their own practices, preferences and values. The following train of thought, separated by commas, flows from the details of the moment on to broader questions about how to stay warm and how to lead a proper life.

The digital watch of the VCR shows 02.20 , already next day and I do not feel tired any more, night is quiet, frost behind the windows, cold, I have wool on me, the electricity of the machines warms, from lamps, does it come from nuclear or coal, I would rather live in the little red [ochre] cottage and grow my food, eat less e-codes and be more, and more naturally, part of nature, everlasting longing for countryside after having spent my childhood there. (SKS KRA, 1999: 297)

In this extract and the next, reflexive thought and judgement are meshed with documentary-style observation typical of the first of our three categories of material engagement. In the following passage, the diarist observes the room and his own body and mind with a seemingly free-floating spirit.

The day is turning into night. I look at this room. There is a lot to improve. Hundred years old house, fireplaces in the corners. Friends have been kind and fetched firewood from the basement that is so difficult to access. The firewood is piled in front of the fireplaces. The system for heating the water does not work, has not worked for the past year. And again today I have not 
decided anything about fixing it. I would like to think of this as a stance on consumption demands, continuous growth, maximisation of profit, the irreversible division between rich and poor. This is how I would like to think, but I wonder if it is just sloppiness. (SKS KRA, 1999: 461)

However, this description is evidently not disinterested: the history of the house seems to matter, people matter as friends, personal characters of integrity and initiative are endorsed. These evaluations depend on an understanding of how things should be, and of practical actions that should be taken. Whilst some comments refer to arrangements within the home, others concern bigger issues including the functioning of the market and related themes of equity and justice. In addition to this movement between social and spatial scales, objects travel from background to foreground and back again, as illustrated in the following extract.

I light up an old Siro-stove (model number 52) manufactured by Högfors. The stove gives a lovely cosy feeling. In winter time like this the fixed electric radiator (from 1972) takes care of the heating of the kitchen. I move to the dining room of our 110-year-old house, and make a fire out of logs in the original 'pönttöuuni' [a type of stove]. The height of our rooms is still 3.4 metres and the stoves too are 3.2. There's a lot to be heated in winters, even though we also partly use electricity ... . When the ignition seems to succeed, I move to the hall where I do the same tasks. (SKS KRA, 2009: 8)

This mode of evaluation and implicit judgement revolves around what MacIntyre describes as the internal value of a practice (MacIntyre, 1984). In short, practices sustain and reproduce specific understandings of what it is to do them well. In so far as practices entail the use of objects, forms of material engagement are woven into the normative framework of the practice itself (Thévenot, 2001). As indicated above, practices are not approached in isolation but are instead linked to more abstract and more strategic questions concerning the structural conditions of social action. In this way the diarists remind us that the practicalities and materialities of daily life are enmeshed in webs of moral judgement.

\section{Object Relations: Insights and Conclusions}

We started with the idea that accounts of everyday life might provide insights and understandings of how materials, practices and practitioners intersect. Our typology - arising from the diary data and from diarists' encounters with things in the world - is useful as a means of promoting and provoking developments in theories of social practice and in the sociological understanding of everyday life. It is so on five counts. First, in detailing the various ways in which material elements figure, our analysis gives a sense of how object relations switch between passive and active forms, and provides an important reminder of the extent to which these relations reflect and reproduce forms of judgement and evaluation regarding the conduct of daily life and the social order as a whole.

Second, our scheme echoes diarists' representations of a world which consists of useful, meaningful and actionable objects-as-tools, on the one hand, and of a more passive material milieu on the other. The latter 'environment' is not organised around actual or possible human-tool combinations, nor does it simply consist of dormant elements 
waiting to be used. It is nonetheless implicated in what people do. In general terms it is clear that 'The physical compositions of humans, artifacts, organisms, and things of nature [...] structure what actions can and might be carried out when, where, how, and for what ends' (Schatzki, 2010: 137). However, it is difficult to determine when and how this kind of pre-configuration occurs or to establish the direction it might take. In writing about how objects switch from latent background to foreground and back again, the diarists describe object-worlds that are constantly in flux, indicating that the emergence (and disappearance) of practical tool-type relationships, and of identifiable modes of prefiguration, are themselves outcomes of the ebb and flow of social practices.

Taking this point further, a third contribution is to highlight the relation between the unknown, the named and the practical aspects of objects. This is a central concern for those interested in the production of value, and in how objects come to be needed, desired and discarded. There seems to be something of a sequence in which objects are initially named (and thus drawn out of the background); in which they become associated with other things and/or with human actors; and in which these associations contribute to more organised chains of action, and to the practical accomplishment of certain valued ends. Conversely, the process of falling out of use appears to be one in which links are eroded or fractured, but in which terms and labels endure for a while longer. Understanding how these bonds are made and broken depends on understanding the emergence (and dissolution) of relevant communities of practice; that is, of groups of people who have some shared understanding of the 'value' of an object, typically related to an also shared capacity to use it/integrate it in practice. Of course some might argue that objects 'create' homogenised collectives and communities of practice around themselves (Wenger, 1998). Either way, it is important to understand how such communities bring object relations into being, and vice versa.

Fourth, diarists' accounts tend to focus on tasks and projects involving the use of many objects at once: they only rarely deal with one object at a time. This is indicative of the actual co-existence of objects and the structures of usefulness and justification that exists around them. In highlighting this feature, the Finnish diarists remind us of the fact that practices are enacted in a world of tools and objects that move in and out of immediate 'usefulness', and that are simultaneously significant as potential resources for future projects and/or as currently redundant remains of past endeavours. In approaching objects in the plural, diarists provide further insight into how things are drawn out of the background (in which they figure as part of the context or environment), how they become topics of immediate attention, and how they sink into the background again. In Ingold's words, 'everything may be something, but being something is always on the way to becoming something else' (Ingold, 2011: 3). As the diarists demonstrate, in the world of materials, nothing is ever complete: materials are thus substances-in-becoming (Barad, 2003: 822). They carry on, overtaking the formal roles that, at one time or another, have been assigned to them.

Finally, in writing about encountering, acting in and evaluating the object-world, diarists inadvertently draw attention to the different temporalities of material engagement. This is a theme that deserves more explicit attention within social theories of practice, and within studies of everyday life. To elaborate, when diarists report on their encounters with the 
material world they report on a world in which objects appear to be stable - they are present-at-hand - suggesting a form of a-temporality. In such accounts, objects appear frozen in time and space, as if caught in a photographic snap-shot. Sometimes there are hints that objects have an active life but, for the most part, diarists writing in this mode rarely refer either to the past or to the future (Beyes and Steyaert, 2011). By contrast, accounts of things in action emphasise both the flow of events and the need for sequencing, synchronisation and temporal coordination. When describing causes and consequences, diarists move back and forth in time, extending the temporal scope of their account well beyond the moment of doing. Practice-theoretical studies do the same: analysing the lives of practices as they unfold over time, and describing the responses and actions of practitioners (those who do) within the ongoing flow of daily life. Finally, those whose accounts are more overtly judgemental move between seemingly universal, atemporal descriptions of how things should be, and more specific evaluations of a particular action or event.

In various guises, time is an already important topic within social practice theory. There has been some discussion of time either as a resource on which practices depend or as something that is made by and through the recurrent enactment of different practices (Shove et al., 2012; Southerton, 2013). Rhythms, sequences and synchronisations are critical in characterising the timespace of practices (e.g. Jalas and Rinkinen, 2013; Shove et al., 2012; Southerton, 2013), and in accounting for their development (Blue, 2013). What is missing, and what the diarists' temporally sensitive accounts of material engagement provide, is an understanding of how the hardware of daily life is situated in time, and how that situating is in part defined by the changing roles that objects play before, within and beyond moments of practical action.

In conclusion, in describing ways of keeping warm on a winter's day, the diarists reveal a range of co-existing but nonetheless distinct modes of material engagement. In this paper we have drawn out these lay theoretical constructs, and drawn attention to their relevance for theoretical development within the social sciences. For sociologists of the everyday, this exercise underlines the centrality of object relations and of their temporal reach: in this it shows that the realm of the everyday is not simply a realm of immediate experience. For theorists of social practice, it provides a more subtle and a more complex account of how material arrangements play out in practice. It does so by recognising forms of material engagement which are evidently not related to the ongoing enactment of specific practices and which resist and are opposed to coherent or rational narrative ordering, but which nonetheless constitute crucial aspects of everyday experience. In addition, it provides an account of how object relations evolve and of how things simultaneously exist as elements in a flat 'background', as dynamic components of ongoing action, and as sites and vectors of judgement and evaluation. This helps fill out an otherwise overly 'functional' view of things which concentrates on moments of use and utility, underplaying their uncertain, ambivalent and contested role in the conduct of daily life, and underestimating the overlapping and multiple temporal registers through which object relations are defined. On all fronts the diarists encourage us not to settle on static schemes and categories, but to focus on the multiplicity of co-existing object relations and to think about how temporal frames swing into and out of view. 
We end with a note on method. Diary collections such as the one we have used effectively turn citizens into ethnographers, valuing and archiving what some might think of as volumes of insignificant detail. For us, the very unstructured nature of the diarywriting process proved crucial. If diarists had been given more direction, and if the Finnish Literature Society had sought to make the diary process 'useful' for research, it would have been difficult and perhaps impossible to map genres and styles of representing object relations or to 'see' the various modes of engagement to which these styles relate - and on which much of our theoretical insight depends.

This brings us to our own role. In working through the diary material, and in sorting it out, we have come up with a three-part scheme, distinguishing between modes of encountering, acting in, and evaluating the object-world. We have been able to use this scheme to some effect, identifying gaps, pointing to new agendas and providing fresh ways of thinking about how people, practices and things interact. Nonetheless, some might accuse us of squashing rich accounts of daily life 'into discrete enclaves of activity and reflection' (Highmore, 2001) and ironically disregarding the complexity and disorder on which our 'analysis' depends. A first response is to reiterate the point that our threepart scheme is a device with which to expand theoretical understanding of object relations in practice. A second is to underline the point that the categories with which we have worked are indeed arbitrary, leaky and co-existent. We have used brief extracts to illustrate and exemplify differences between modes of representing and relating to things but in most of the diaries writers move with ease between passages of 'flat' documentary description, practical talk of doing and coping, and reflexive judgement.

In switching between different 'voices', diarists are engaged in various forms of involvement and presentation of self. Not surprisingly, those who write about practical projects and accomplishments frequently present themselves as competent, clever and thoughtful actors capable of managing the challenges of daily life and of providing useful advice to others: in short, doing and evaluation are never far apart. In addition, it is important to remember that diary writing is a process in its own right. The business of documenting and cataloguing the experiences of the day often prompts reflection and evaluation of one's own routine. These features, along with endless inconsistencies, make the diary data what it is. They also make it a useful resource, allowing us to catch sight of how material objects and social practices hang together.

\section{Funding}

This research was supported by the Academy of Finland (grant number 140938), and by the UK's Engineering and Physical Sciences Research Council (grant number EP/K011723/1) as part of the RCUK Energy Programme and by EDF as part of the R\&D ECLEER Programme. 


\section{References}

Alaszewski A (2006) Using Diaries for Social Research. London: Sage.

Appadurai A (ed) (1988) The Social Life of Things: Commodities in Cultural Perspective. Cambridge: Cambridge University Press.

Barad K (2003) Posthumanist performativity: Toward an understanding of how matter comes to matter. Signs 28(3): 801-831.

Becker HS (1974) Art as collective action. American Sociological Review 39: $767-$ 776. Becker HS (1984) Art Worlds. Berkeley, CA: University of California Press

Belk R (1988) Possessions and the extended Self. Journal of Consumer Research 15: 139-168.

Beyes T and Steyaert C (2011) Spacing organization: non-representational theory and performing organizational space. Organization 19(1): 45-61.

Blue S (2013) Scheduling routine: An analysis of the spatio-temporal rhythms of practice in everyday life. $\mathrm{PhD}$ Thesis, Lancaster University, $\mathrm{UK}$.

Bourdieu P (1990) The Logic of Practice. Cambridge: Polity. Collins R (2004) Interaction Ritual Chains. Princeton, NY: Princeton University Press.

Crang M (2005) Qualitative methods (part 3): there is nothing outside the text? Progress in Human Geography 29(2): 225-233.

De Certeau M (1984) The Practice of Everyday Life. Berkeley, CA: The University of California Press.

Douglas M and Isherwood B (1980) The World of Goods: Towards an Anthropology of Consumption. Harmondsworth: Penguin Books.

Durkheim E (1915[2012]) The Elementary Forms of the Religious Life. Mineola, NY: Dover Publications.

Engestrom Y and Blackler F (2005) On the life of the object. Organization 12(3): 307330.

Garfinkel H (1996) Ethnomethodology’s program. Social Psychology Quarterly 59(1): 521.

Goffman E (1967) Interaction Ritual: Essays in Face-to-Face Behavior. Chicago, IL: Aldine.

Gregson N, Metcalfe A and Crewe L (2009) Practices of object maintenance and repair. How consumers attend to consumer objects within the home. Journal of Consumer 
Culture 9(2): 248-272.

Hand M and Shove E (2007) Condensing practices Ways of living with a freezer. Journal of Consumer Culture 7(1): 79-104.

Highmore B (2001) Obligation to the ordinary: Michel de Certeau, ethnography and ethics. Strategies: Journal of Theory, Culture \& Politics 14(2): 253-263.

Highmore B (2002) Everyday Life and Cultural Theory. An Introduction. London: Routledge.

Ingold T (2008) When ANT meets SPIDER: social theory for arthropods. In: Knappett C and Malafouris L (eds) Material Agency: Towards a Non-Anthropocentric Approach. New York, NY: Springer, 209-215.

Ingold T (2011) Introduction. In: Ingold T (ed) Redrawing Anthropology: Materials, Movements, Lines. Farnham: Ashgate, 1-20.

Ingold T (2012) Toward an ecology of materials. Annual Review of Anthropology 41: $427-442$.

Jalas M and Rinkinen J (2013) Stacking wood and staying warm: Time, temporality and house-work around domestic heating systems. Journal of Consumer Culture. Epub ahead of print 11 November 2013. DOI: 10.1177/1469540513509639.

Jokinen E (2004) The makings of mother in diary narratives. Qualitative Inquiry 10(3): $339-359$.

Latham A (2003) Research, performance, and doing human geography: Some reflections on the diary-photograph, diary-interview method. Environment and Planning A 35(11): 1993-2017.

Latour B (1992) Where are the missing masses? The sociology of a few mundane artefacts. In: Bijker WE and Law J (eds) Shaping Technology/Building Society: Studies in Sociotechnical Change. Cambridge, MA: MIT Press, 225-258.

Lefebvre H (1947[1991]) Critique de la vie quotidienne. Introduction [The Critique of Everyday Life]. London: Verso.

Lejeune P (2009) On Diary. Hawaii: University of Hawaii Press.

MacIntyre A (1984) After Virtue. Notre Dame: University of Notre Dame Press.

Meth P (2003) Entries and omissions: using solicited diaries in geographical research. Area 35(2): 195-205.

Morrison C-A (2012) Solicited diaries and the everyday geographies of heterosexual love andhome: reflections on methodological process and practice. Area 44(1): 68-75. 
Oliver J (1958) The use of weather diaries in the study of historic climates. Weather 13(8): 251-256.

Pink S (2012) Situating Everyday Life: Practices and Places. London: Sage.

Reckwitz A (2002a) The status of the 'material' in theories of culture: From 'social structure' to 'artefacts'. Journal for the Theory of Social Behaviour 32(2): 195-217.

Reckwitz A (2002b) Toward a theory of social practices. European Journal of Social Theory 5(2): 243-263.

Schatzki TR (1996) Social Practices: A Wittgensteinian Approach to Human Activity and the Social. Cambridge: Cambridge University Press.

Schatzki TR (2001) Introduction: Practice theory. In: Schatzki T, Knorr Cetina K and von Savigny E (eds) The Practice Turn in Contemporary Theory. London: Routledge, 114.

Schatzki, T. (2002). The site of the social: A philosophical exploration of the constitution of social life and change.

Schatzki T (2010) Materiality and social life. Nature and Culture 5(2): 123-149.

Sheringham M (2006) Everyday life: Theories and Practices from Surrealism to the Present. Oxford: Oxford University Press.

Shove E, Pantzar M and Watson M (2012) The Dynamics of Social Practice: Everyday Life and it Changes. London: Sage.

SKS KRA (Finnish Literature Society Folklore Archives) (1999) Diary: Suomalaisen päivä - kirjoitushanke [The Day of the Finn - writing initiative]. Helsinki: SKS KRA.

SKS KRA (Finnish Literature Society Folklore Archives) (2009) Diary: Suomalaisen päivä - kirjoitushanke [The Day of the Finn - writing initiative]. Helsinki: SKS KRA.

Southerton D (2006) Analysing the temporal organization of daily life: Social constraints, practices and their allocation. Sociology 40(3): 435-454.

Southerton D (2013) Habits, routines and temporalities of consumption: From individual behaviours to the reproduction of everyday practices. Time \& Society 22(3): 335-355.

Stanley L (1995) The Auto/Biographical I: The Theory and Practice of Feminist Auto/Biography. Manchester: Manchester University Press.

Thévenot L (2001) Pragmatic regimes governing the engagement with the world. In: Schatzki T, Knorr-Cetina K and von Savigny E (eds) The Practice Turn in Contemporary Theory.London: Routledge, 56-73. 
Warde A (2005) Consumption and theories of practice. Journal of Consumer Culture 5(2): 131-153.

Watson M and Shove E (2008) Product, Competence, Project and Practice DIY and the dynamics of craft consumption. Journal of Consumer Culture 8(1): 69-89.

Wenger E (1998) Communities of Practice: Learning, Meaning, and Identity. Cambridge: Cambridge University Press.

Jenny Rinkinen is a PhD Candidate in the Department of Management Studies at Aalto University School of Business. Her research focuses on material and temporal dimensions of social practices in understanding the dynamics of energy demand.

Mikko Jalas is a Senior Lecturer in the Department of Design at Aalto University School of Arts, Design and Architecture. His research focuses on time use, materiality and everyday life and their implications for sustainable consumption practices.

Elizabeth Shove is Co-Director of the DEMAND research centre (Dynamics of Energy, Mobility and Demand) and Professor of Sociology at Lancaster University. Her recent research has been about how social practices change and about the implications of these dynamics for everyday life, energy demand and climate change.

Date submitted August 2014

Date accepted February 2015 